\title{
KONSTRUKSI MASKULINITAS DALAM CERITA RAKYAT JAWA
}

\section{${ }^{1}$ Arif Mashudi dan ${ }^{2}$ Muhammad Edy Thoyib}

\author{
${ }^{1}$ Nahdia Aurelia Aurita \\ ${ }^{2}$ Universitas Islam Negeri Maulana Malik Ibrahim Malang \\ ${ }^{1}$ nahdiaaurita@gmail.com
}

\begin{abstract}
This article discusses how to analyze the construction of masculinity in Javanese folklore. The data source in this research is Javanese folklore in fairytale ceritarakyat.com. This article is a review of literary criticism using qualitative approach methods. The cornerstone of the theory in this study is some masculinity by R.W Connell. This theory explains that the pattern of masculinity is always different depending on the culture and era. The results showed that Javanese folklore constructs several different masculinities. This shows that masculinity is very complex. Although originating from the same cultural roots, the pattern of masculinity in Javanese folklore is not homogeneous and simple.

Keywords: Construction, folklore, masculinity, various masculinity.
\end{abstract}

\section{Abstrak}

Artikel ini bertujuan untuk menganalisis konstruksi maskulinitas yang ada di dalam cerita rakyat Jawa. Sumber data dalam penelitian ini berupa cerita-cerita rakyat Jawa yang ada di dalam dongeng ceritarakyat.com. Artikel ini merupakan kajian kritik sastra dengan menggunakan pedekatan metode kualitatif. Landasan teori dalam penelitian ini adalah multiple masculinities oleh R.W. Connell. Teori ini menjelaskan bahwa pola maskulinitas selalu berbeda-beda tergantung pada kebudayaan dan masanya. Hasil penelitian menunjukkan bahwasanya cerita-cerita rakyat Jawa menkonstruksi beberapa maskulinitas yang berbeda-beda. Hal ini menunjukkan bahwa maskulinitas merupakan hal yang sangat kompleks. Meskipun berasal dari akar kebudayaan yang sama, pola maskulinitas dalam cerita rakyat Jawa tersebut tdak homogeny dan sederhana.

Kata Kunci: Konstruksi, cerita rakyat, maskulinitas, multiple masculinities.

\section{PENDAHULUAN}

Maskulinitas dan feminitas sebelumnya pada tahun 1980 dideskripsikan sebagai ciri-ciri kepribadian yang dianggap pantas dan hanya spesifik bagi jenis kelamin tertentu. Bentuk ekpresi dari ciri kepribadian ini berupa perilaku (Schrock \& Schwalbe, 2009:278). Kemudian pada tahun 1985, Carrigan dkk mengatakan dalam tulisannya yang berjudul Toward a New Sociology Masculinity bahwa maskulinitas bukanlah ciri keperibadian, namun kebiasaan kolektif laki-laki. 
Connell (2000) mencetuskan teori yang disebut multiple masculinities, yang mengatakan bahwa pola maskulinitas akan berbeda tergantung pada lingkup sosialnya. Konstruksi maskulinitas juga akan berbeda tergantung pada kebudayaan dan periode sejarahnya. Dalam teori ini dikatakan bahwa dalam masyarakat multikultural berskala besar, sangat mungkin bila definisi maskulitas tidak hanya ada satu. Connell juga mengatakan bahwa lebih dari satu jenis maskulinitas dapat ditemukan dalam lingkup budaya tertentu (Connell, 2002: 16-17). Berdasrkan teri Carrigan dan Connell tersebut, ditarik kesimpulan bahwa maskulinitas merupakan kebiasaan kolektif laki-laki yang begitu beragam dan kompleks. Kebiasaan kolektif ini meruoakan permianan performatif yang dilakukan melalui legitimasi dari rekan sejawat, atau sesame laki-laki dalam suatu lingkup social, dan terdiri dari kumpulan-kumpulan bentuk ideal dari maskulinitas yang dianggap benar dan diterima. Karena konstruksi maskulinitas pada tiap kebudayaan berbedda, maka klasifikasi maskulinitas dalam penelitian ini tidak didasarkan pada teori tertentu, tetapi, akan diklasifikasikan berdasarkan hasil temuan analisis.

Cerita rakyat (folktale) adalah salah satu bagian dari folklore (folklore). Martha dan martine (2011) berpendapat bahwa cerita rakyat adalah bagian dari folklore yang berjenis verbal folklore atau folklor lisan. Beberapa bentuk dari folklore lisan yang dipelajari oleh folkrolist adalah folk song, mitos, dan verita rakyat. Tidak diturunkan dari satu generasi ke generasi lainnya melalui mulut ke mulut.

Cerita rakyat secara umum menurun disampaikan kepada rakyat Indoensia. Cerita rakyat merupakan sarana yang ampuh yang melaluinya anak-anak dapat belajar mengenai warisan budaya, kepercayaan masyarakat, adat istiadat, dan tradisi mereka. Cerita rakyat juga digunkaan oleh masyarakat untuk menyampaikan pesan-peasan kepada generasi muda. Sebagai contoh, orang tua menceritakan kisah Malin Kundang, kepada anak merreka untuk mengajarkan betapa pentingnya kepatuhan terhadap orang tua. Kemudian ketika anak-anak tersebut beranjak dewasa, pelajaran yang mereka dapat juga akan mereka sampaikan kepada genersi berikutnya.

Cerita rakyat merupakan medium pembelajaran awal mengenai gender. Martin dan Rubble (2004) mengatakan bahwa anak kecil merupakan detektif gender yang tengah mencari teladan mengenai gender- siapa yang semestinya ikut serta dalam aktivitas tertentu, siapa yang tidak, siapa yang bias bermain dengan siapa, bagaimana gender tertentu harus bersikap, dan mengapa perempuan dan laki-laki berbeda. Cerita rakyat memiliki peranan yang sangat penting dalam pendidikan anak-anak, dank arena itulah banyak hal yang dapat ditelaah dalam cerita rakyat. Dalam cerita rakyat Jawa sendiri, terdapat konstruksi maskulinitas: bagaimana harapan masyarakat terhadap laki-laki, bentuk ideal dari maskulinitas, sifat-sifat seperti apa yang diberikan kepada laki-laki, dan anggapan masyarakat terhadap laki-laki. Oleh karena itu, konstruksi maskulinitas dalam cerita rakyat Jawa asngat penting untuk dikaji. 


\section{METODE PENELITIAN}

Kajian ini memanfaatkan teori R.W. Connell tentang multiple masculinities untuk menganalisis cerita rakyat Jawa. Sumber data didapat dari beberapa kalimat dan ujaran-ujaran yang ada dalam cerit. Metode penelitian di dalam artikel ini menggunakan metode close reading, yakni cerita-cerita yang telah disebutkan dibaca sebanyak tiga kali dan kemudian dianalisis berdasarkan beberapa kriteria yang berhubungan dengan representasi maskulinitas yang ada dalam cerita rakyat tersebut. Kriteria tersebut adalah menganalisis ciri-ciri fisik dan karakteristik tokoh-tokoh laki-laki dalam cerita rakyat tersebut.

Selama proses close reading ide dan gagasan yang berhubbungan dengan kriteria di atas akan ditandai kemudian dicatat, dan akan diulas kembali ketika proses close reading telah selesai.

Obyek kajian dalam penelitian ini adalah tiga buku yang berjudul Bawang Merah dan Bawang Putih dan Dongeng Terkenal Lainnya, Legenda Keong Emas, dan Kumpulan Cerita Rakyat Nusantara. Dari buku Bawang Merah dan Bawang Putih dan Dongeng terkenal Lainnya, diambil cerita Nyi Roro Kidul dan Sangkuriang Sakti. Dari buku legenda Keong Emas diambil cerita Keong Emas, Jaka Tarub dan Tujuh Bidadari, ratu Laut Selatan, dan Asal Mula Candi Prambanan. Kemudian dalam buku Cerita Rakyat Nusantara, cerita yang diambil adalah Cerita Gunung Merapi.

\section{PEMBAHASAN}

Meskipun memilikki kebudayaan yang sama, namun dalam cerita rakyat Jawa maskulinitas dikontruksi dengan cara yang berbeda-beda. Berikut adalah jenis-jenis konstruksi maskulinitas cerita rakyat Jawa:

1. Kesatriaan

Ciri-ciri kesatriaan diambil dari kodel kasatria leh Myss yakni keberanian, kehormatan, kesopnanan, keadilan, dan rasa ingin menolong yang besar. Dalam cerita, model kesatria seringkali menolong dan melindungi karakter perempuan. Mereka juga biasanya pergi berperang dengan tujuan yang terhormat dan mulia.

Dalam cerita Jaka Tarub dan Tujuh Bidadari, lelaki harus memiliki sifat berani dan bertanggung jawab layaknya kesatri. Hal ini dapat dilihat daridialog antara Dewi Rasa Wulan dan Ki Ageng Gribig:

"Hei Kisanak! Kau telah berbuat curang terhadapku! Turunlah jika kau memang berwatak kstaria." (Hal.59)

Dari kalimat di atas dapat dilihat bahaw ada ekspektasi tertentu terhadap seseorang laki-laki; yakni untuk bersifat berani dan bertanggung jawab layaknya sesorang kesatria. Ki 
Ageng Gribig memnuhi ekspektasi tersebut, pada akhirnya ia bertanggung jawab terhadap Dewi Rasa Wulan.

Pada cerita yang sama, Jaka Tarub menghampiri Nawang Wulan yang tengah menangis di tengah telaga karena pakaiannya hilang. Kemudian Jaka Tarub memberikan pertolongan kepada Nawang Wulan.

"Oh sungguh malang nasibmu..Aku bermaksud menolongmu, kalau kau mau menerimanya." (hal. 65)

Meskipun Jaka Tarub menolong Nawang Wulan tidak dengan niat yang yang tulus, namun karena ia mengharapkan sesuatu, namun pada akhirnya Jaka Tarub memang mendapatkan hal yang diinginkannya; pernikahan dengan Nawang Wulan. Hal ini menunjukkan bahwa meskipun dengan niat yang buruk, tapi jika seorang laki-laki menunjukkan sikap kekesatriaan, ia akan tetap mendapatkan hal yang ia inginkan.

Selanjutnya dalam cerita Keong Emas, Raden Inu Kertapati juga memiliki sifat kesatria. Setelah Chandrakirana diusir dari istana, Raden Inu Kertapati berkelana untuk mencari kemana perginya Chandrakirana. Ia tahu bahwa Chandarakirana sedang dalam kesusahan dan berniat untuk menemukan dan melindungi wanita itu. Raden Inu juga menolong seorang kakek tua yang tengah kelaparan dengan mencarikannya makanan. Ini merupakan salah satu ciri model ksatria, yakni keinginan menolong yang besar.

\section{Jiwa Petualang}

Dalam beberapa cerita rakyat Jawa, tokoh-tokoh pria dikisahkan sebagai pribadi yang suka berpetualag, berburu, dan berkelana. Hal tersebut bias dilihat di dalam beberapa ujaran dan jalan cerita di dalam cerita.

Dalam cerita Jaka Tarub dan Tujuh Bidadari, Ki Ageng Gribig, yang merupakan ayah dari Jaka Tarub lebih memilih pergi berpetualang ke seluruh tanah Jawa dari pada merawat dan membesarkan putraya.

“Nyi Randa Tarub...! Apakah kau menginginkan seorang anak? Tanya lelaki yang tak lain adalah Ki Ageng Gribig itu.

"Kisanak ini siala?" Tanya Nyi Randa Tarub dengan heran.

"Aku adalah ayah dari anak ini. Tapi aku tidak bias memeliharanya sekarang ini. Karena aku masih harus berkelana ke seluruh Tanah Jawa. Maukah kau membesarkan anak ini?.

"Kisanak tentu saja aku mau, sudah lama aku mendambakan seorang anak. (hal 62)

Dari paragraph di atas cerita di atas dapat dilhat bahwa lai-laki lebih memilih berpetualang dari pada merawat anaknya sendiri. Terlepas itu keinginannya sendiri untuk mengembara ataupun itu adalah sebuah kebutuhan.

Jiwa petualang juga dapat di tokoh laiki-laki di dalam cerita Sangkuriang Sakti. Ketika masih kecil, Sangkuriang diceritakan sudah pandai berburu. 
Tak terasa tujuh tahun berlalu. Sangkuriang kecil sudah pandai berburu bianatang bersama si Tumang. (hal. 50)

Laki-laki, meskipun muda sudah terampil berburu. Ketika Sangkuriang sudah tumbuh dewasa pun, Sangkuriang pergi mengembara.

Sangkuriang bertekad tidak akan kembali ke rumah. Ia mengembara tak tentu arah sampai kahirnya bertemu dengan seorang pertapa sakti. Ia diangkat sebagai murid terkasih. Semua ilmu kesaktian pertapa itu diwariskan kepada Sangkuriang. Dua belas tahun kemudian ia sudah menjadi pemuda dewasa, wajahnya tampan, tubuhnya perkasa. (hal.49)

Raden Inu Kertapati di dalam cerita Keong Emas juga pergi mengembara untuk menemukan Dewi Chandrakiranaa yang diusir dan diasingkan dari istana oleh ayahnya karena telah dianggap telah berbuat jahat.

"oh dinda Chandrakirana....dimanakah engkau gerangan berada?" berkali-kali pemuda itu mendesah. Pemuda itu tak lain adalah raden Inu Kertapati. Ia telah mengembarake berbagai desa untuk mencari Chandrakirana yang telah hilang dari istana. (hal. 27)

Dari ujaran dan juga kalimat di atas dapat dilihat bahwa bagaimanapun seorang laki-laki akan memilih untuk pergi mengembara ataupun berpetualang untuk memenuhi keinginannya.

Jiwa petualang juga terdapat di dalam cerita Gunung Merapai. Ketika Panembahan Senapati diutus untuk mengembara oleh Ki Juru Mertani.

"Kalau begitu berpatalah lagi" kata Ki Juru Mertani. Ki Juru Mertani melanjutkan perkataannya "hanyutkanlah sebatang kayu di sungai. Naiklah kau di atas kayu tersebut. Setelah samai di laut selatan kauakan menjumpai Ratu Kidul". Panembahan Senapati menjalankan apa yang dikatakan Ki Juru Mertani.

Laki-laki diberikan kecenderungan untuk pergi berburu atau berkelana bahkan semenjak kecil. Mereka lebih memilih berkelana dari pada merawat dan membesarkan anak. Dari pada sifat seorang pengasuh, laki-laki cenderung diberikan sifat petualang.

\section{Tempramental dan Kesombongan}

Kekrasan, kekuasaan, temperamen, dan dominasi sangat erat kaitannya dengan bagaimana maskulinitas dikontruksi di dunia Barat (Beiras et.al, 2015: 1526), namun ternyata di Jawa maskulinitas juga dikontruksi seperti ini. Terbukti dai beberaoa kata, kalimat, frasa, dan dialog yang ditemukan sebagai berikut.

Prabu Galuga dalam cerita Sangkuriang Sakti adalah seorang yang mudah tersulut amarahnya. Ketika anak peempuannya, Dayang Sumbi menolak lamaran beberapa laki-laki, Sang Prabu seketika marah dan memberikan Dayang Sumbi dua pilihan:

...Kecantikan Nyi Dayang SUmbi terkenal sampai ke Negara tetangga, hamoir setiap pecan dating lamaran; namun Nyi Dayang Sumbi selalu menolaknya. Sang Prabu 
menjadi marah sekali. "Sumbi hanya ada dua pilihan bagimu. Mau menikah atau kuasingkan kau di tepi hutan." Karena gadis itu tetap tak mau menikah maka Ia diasingkanng di tepi hutan....(hal.49)

Dalam cerita yang sama, Sangkkuriang, yang merupakan anak dari Dayang Sumbi juga memiliki sifat sangat mudah dikuasai amarah. Ketika anjing yang diajaknya berburu menolak untuk menangkap babi hutan yang kabur, Ia menjadi sangat marah hingga Ia membidikan panahnya kkea rahTumang, anjing tersebut. Sangkuriang kemudian menyembelih anjing tersebut dan mengambil bagian-bagian tertentu untui dimakan.

Ketika dewasa, Sangkuriang melamar seorang wanita yang ternyata adalah ibunya sendiri. Mengetahui hal tersebut sang ibu menyuruh Sangkuring untuk membangun sebuah telaga dan perahu dalam satu malam dengan harapan bahwa Sangkuriang akan gagal. Namun ketika Ia melihat Sangkuriang akan menyelesaikan perahu itu dalam waktu semalam, Dayang SUmbi bermuslihat dengan menumbuk padi sehingga orang lain mengira fajar telah tiba. Ketika Sangkuriang mengetahui bahwa dirinya telah ditipu oleh Dayang Sumbi, laki-laki itupun marah dan menendang perahu buatannya sehingga perahu tersebut telungkup ke arah bumi dan kemudian menjadi gunung.

Dalam cerita Asal Mula Candi Prambanan, saat Bandung Bandawasa memenangkan peperangan melawan pasukan Raja Baka, Ia segera pergi ke kerajaan Prambanan. Ketika sampai di sana Ia tertarik dengan Roro Jonggrang, namun Rara Jonggrang membenci lelaki itu karena Ia telah membunuh ayahnya. Rara Jonggrang tidak berani mengatakan hal tersebut karena Ia takut Bandung Bandawassa akan melakukan sesuatu padanya.

Ingin Ia mengatakan 'aku bendi padamu karena kau telah membunuh ayahku' namun lidahnya terasa kelu. Bagaimanapun sebagai perempuan Ia takut dirinya nanti dianiaya jika Bandung Bandawasa mengetahui isi hantinya (hal. 114)

Dari paragraf di atas, dapat dilihat bahwa laki-laki, bahkan laki-laki yang belum dikenalpun dianggap sebagai makhluk yang temperamental dan mudah melakukan kekerasan terhadap wanita ataupun orang disekitarnya. Pada akhirnya terbutki bahwa Bandung Bandawasa memang seperti prasangka Rara Jonggrang. Ketika Ia mengetahui bahwa Rara Jonggrang telah menipunya dan membuatnya gagal menyelesaikan seribu candi, ia marah besar

“Ampun Raden... hamba hanya menjalankan perintah!" kata salah seorang pemuda.

"Siapa yang memerintahkan kalian?"

"Bibik Emban pengasuh Dewi Roro Jonggrang"...

Berkata demikian Bandung Bandawasa mengibaskan lengannya. Seketika puluhan pemuda di depannya berjatuhan ke tanah sambil muntah darah. Banyak di antara mereka yang langsung mati... Bandung Bandawasa berdiri tegak di hadapan Dewi Roro Jonggrang Nampak ketakutan. Ia mundur beberapa langkah. Bandung Bandawasa mendekati gadis yang dicintainya dan berkata... Ucapan pemuda sakti itu tak bias ditarik lagi. Seketika Dewi Roro Jonggrang berubah menjadi batu besar di candi Prambanan. Bandung Bandawasa juga mendatangi anak-anak gadis di sekitar Prmabanan yang 
diperintah membunyikan lesung. Dengan penuh amarah para gadis itu dikutuk Bandung Bandawasa.... (hal. 119-120)

Kesombongan juga merupakan salah astu sifat yang diberikan kepada laki-laki dalam beberapa cerita rakyat. Dalam Asal Mula Candi Prambanan, Raja Boko ayah dari Roro Jonggrang memiliki sifat sombong. Ia mempercayai bahwa Ia adalah orang yang tidak mungkin terkalahkan. Ketika Roro Jonggrang berkata bahwa Ia tidak akan menikah sebelum kerajaankerajaan Pangging kalah dalam peperangan, Raja Boko dengan percaya diri berkata bahwa ia sendiri yang akan memimpin peperangan sehingga pasukannya menang. Ketika sampai di medan peperangan, Raja Boko menyuruh seluruh prajurit untuk lari ke belakangnya, membuat sang raja berada di barisan paling depan dalam peperangan. Ketika Bandung Bandawasa mengahdangnya, Raja Boko masih percaya bahwa dia tidak akan kalah:

“Hai Raja Boko, akulah lawanmu!" tantang Bandung Bandawasa sambil menudingkan tanggannya"

"Aha...anak muda kemarin sore berani menantangku?" Kata Raja Boko dengan sombongnya.

Raja Boko mengayunkan tangan kanannya bermaksud menyambar leher Bandung

Bandawasa... (hal. 112)

Sifat arogan yang dimiiki Raja Boko menyebabkan kekalahan Candi Prambanan. Namun sifat arogan dan sombong ternyata juga dapat memberikan kemenangan.

Salah satu contohnya adalah Bandung Bandawasa. Bandung Bandawasa bersikeras untuk mengikuti peperangan. Meyakini bahwa diirnya sakti. Kemudian ketia Ia dalam perjalanan menuju ke medan perang, Bandung Bandawasa dihadang oleh raksasa, bukannya menghindar sehingga Ia bias mencapai medan perang lebih cepat, namun Bandung Bandawasa justru malah menantang, raksasa itu.

"Siapa kau tampakkan wujudmu!" bentak Joko Bandung.

"Hoo...sombong sekali kau anak muda! Apakah nyawamu berangkap tujuh?"

"Aku tak takut dengan segala setan belang maupun raksasa pengecut yang tak mau menampakkan diri” (hal.109)

Pada kahirnya Bandung Bandawasa bertarung dengan menang melawan raksasa itu. Ia justru malah mendapatkan kekuatan sang raksasa, yang nantinya membuatnya menang melawan Raja Boko. Hal ini menunjukkan bahwa sifat arogan dimiliki oleh setiap karakter lakilaki, da nada saatnya sifat arigan seperti itu membuat laki-laki mendapatkan hal yang mereka inginkan.

Dapat disimpulkan dari analisis di atas bahwa layaknya di Barat, dalam beberapa cerita rakyat Jawa pun maskulinitas dikonstruksi dengan memberikan dan menilai bahwa laki-laki memiliki sifat-sifat seperti mudah dipicu amarahnya, arogan, dan cenderung mengambil jalan kekerasan jika mereka sudah dibutakan oleh amarah. 


\section{Keras Kepala dan Agresif}

Sudah tidak asing lagi ketika laki-laki dianggap sebagai pribadi yang keras kepada dan agresif. Beberapa sifat laki-laki adalah dominan, kuat, agresif, aktif melakukan banyak hal dan rasional (Kurnia, 2004). Dalam cerita rakyat Jawa laki-laki juga dikontruksi dengan sifat-sifat tersebut, terutama agresif dan keras kepala.

Sikap agresif dank eras kepala digambarkan sebagai salah astu sifat dasar laki-laki dalam cerita Asal Muda CAndi Prambanan Joko Bandung bersikeras untuk turun tangan dalam peperangan dan melawan tentara-tentara Raja Boko.

"Kalau memang pasukan Pengging tidak mampu, ananda sendiri yang akan maju ke medan perang. "tegas Joko Bandung"

"ANakku, ingatlah, penguasa negeri Prambanan itu bukan sembarang raja. Ia adalah seorang raja yang sakti mandraguna. Tubuhnya tinggi besar seperti raksasa." Ucap ayah Joko Bandung untuk mengingatkan anaknya.

"Ananda tidak takut ijinkanlah ananda berangkat ke negeri Prambanan menyusul paman Patih Sinduro." (hal.165)

Masih di dalam cerita Asal Usul Candi Prambanan, Raja Boko menunjukkan sifat agresifnya.

"Baiklah, kalau begitu aku sendiri yang akan memimpin prajurit pilihanku ke medan perang."

"Hamba ikut serta Rama Prabu..."

"Wah tidak boleh, kau cukup menunggu di istana. Percayalah aku pasti bias mengalahkan orang-orang Pengging!"

"Baiklah Rama, do'a hamba menyertai Rama ke medan perang."

Demikianlah Raja Boko maju ke medan perang. Dalam tempo yang tidak terlalu lama Ia sudah berada di tengah-tengah medan perang (hal. 106-107)

Dari kisah Joko Bandung dan Raja Boko sikap agresif dank eras kepala adalah salah satu sifat yang sudah melekat terhaap laki-laki. Terlepas sifat itu akan membawa hal positif atau negative terhadap iri mereka, sifat keras kepala dan agresif masih belum bias terpisah dari tokoh-tokoh laki-laki.

Dalam cerita Sangkuriang Sakti, tokoh Sangkuriang digambarkan sebagai sosok yang agresif dank eras kepala. Ketika Dayang Sumbi yang tak lain adalah ibunya sendiri mengatakan bahwa mereka tidak seharusnya melanjutkan hubungan mereka karena Sangkuriang adalah anak dari Dayang Sumbi. Namun Sangkuriang masih tetap bersikeras untuk menikahi dayang Sumbi.

"kalau begitu kau adalah Sangkuriang anankku sendiri!" pekik gadis itu yang tak lain adalah dayang Sumbi keturunan bidadari yang tetap awet muda. Tidak mungkin aku menikah dengan anakku snediri" kata Dayang Sumbi. Sangkuriang tak percaya dan terus mendesak agar Dayang Sumbi agar mau menjadi istrinya....(hal.49) 


\section{Bijaksana dan Tegas}

Salah satu bentuk ideal dari maskulinitas yang ada dalam cerita rakyat Jawa adalah kebijaksanaan. Dalam cerita Keong Emas, salah seorang karakter laki-laki, yakni Raja Airlangga digambarkan sebagai seseorang yang arif dan bijaksana dan tidak mudah dikuasai amarah.
Airlangga merupakan seorang raja yang bijaksana. Tatkala puteri mahkota, Sang garmawijaya Dharma Prasadottunggadewi menolak menggantikan takhta kerajaan. Airlangga tidak lantas marah. Ia justru membangun sebuah pertapaan di Pucangan karena puterinya itu memilih penghidupan sebagai pertapa. (hal.7)
Rama Prabu, yang keturunan dari Raja Airlangga merupakan seorang raja yang tegas. Ketika bukti dan saksi menunjkkan bahwa Chandrakiranalah yang meracuni dirinya, Rama Prabu tetap menghukum Chandrakirana meskipun Ia adalah anak kesayangan Rama Prabu:

Hukum harus ditegakkan di kerajaan ini. Tak terkecuali terhadap anakku sendiri (hal.17)

Ketegasan dan kebijaksanaan merupakan salah satu bentuk maskulinitas yang dibangun dalam cerita ini.

\section{KESIMPULAN}

Setelah beberapa cerita rakyat Jawa dianalisis untuk meiihat bagaimana cerita-cerita tersebut mengkonstruksi maskulinitas, ditemukan bahwa ada lima jenis konstruksi maskulinitas yang dalam cerita rakyat Jawa: kekastriaan, jiwa petualang, temperamental dan kesombongan, keras kepala dan agresif, dan yang terakhir ada kebijaksanaan. Konstruksi maskulinitas berbeda-beda pada tiap kebudayaaan dan masa. Bahkan dalam akar kebudayaan yang sama, seperti contohnya dalam kebudayaan Jawa, konstruksi maskulinitas bias saja berbeda. Hal ini menunjukkan bahwa maskulinitas sangatlah kompleks.

\section{DAFTAR PUSTAKA}

Beiras, A. Cantera, L.M, De Alenca Rodrigues, Roberta. (2015). I Am a Bull! The Construction of Masculinity in a Group of Men Perpetrators of Violence Against Women. University Psychologia-Edicion Especial. 14 (15). Hal 1525-1537.

C. Sims, Martha., Stephene, Martine. (2011). Living Folklore. Second Edition. Logan, Utah; Utah State University Press.

Carrigan, T., Connell, B., Lee,J. (1985). Toward a New Sociology of Masculinity. Theory of Society. 14 (5). Hal. 551-604.

Ikranegara, T. (2016). Legenda Keong Emas. Dua Media: Surabaya.

Ikranegara, Y. (2016). Kumpulan Cerita Rakyat Nusantara. Dua Media: Surabaya. 
Kurnia, Novi. (2004). Representasi Maskulinitas dalam Iklan. (Jurnal Ilmu Sosial dan Politik). 8 (1). Hal 17-36.

Schrock, D., Schwalbe, M. (2009). Men, Masculinity, and Manhood Acts. The Annual Review and Sociology. 35. Hal 277-295.

Tim Kreatif Lintas. Dongeng Pengantar Tidur Bawang Merah Bawang Putih dan Dongeng Terkenal Lainnya. Lintas Media Jombang: Jombang. 